ISSN : $2354-6034$ (Print)

ISSN : 2599 - 0187 (Online)

\title{
ANALISIS PENGUNGKAPAN INFORMASI AKUNTANSI TERHADAP BIAS INVESTOR DALAM MENAFSIRKAN AKRUAL
}

\author{
Norliyani Aulia \\ Universitas Islam Negeri Sunan Kalijaga Yogyakarta \\ Email: aulia.norliyani@gmail.com
}

\begin{abstract}
In an investment activity can sometimes cause errors in the process of perceiving information related to investment. This is caused by bias so that it can cause market anomalies. Perception bias is a person's a psychological condition that tends to be not objective in perceiving something. Someone who is a state of bias believe in its ability to accurately evaluate events, including making judgements about the situation in terms of investment. In addressing the bias, accounting information disclosure needs to be done. This research uses descriptive research and documentation data collection techniques. In the delivery of accounting information must be high quality standards of accounting and finance and non-financial disclosures.
\end{abstract}

Keywords: Accounting Information, Investor Bias, Accruals.

\begin{abstract}
ABSTRAK
Dalam suatu kegiatan investasi terkadang dapat menyebabkan kesalahan dalam proses mempersepsikan informasi terkait dengan investasi. Hal ini disebabkan oleh bias sehingga dapat menyebabkan anomali pasar. Bias persepsi adalah kondisi psikologis seseorang yang cenderung tidak objektif dalam memahami sesuatu. Seseorang yang memiliki bias percaya pada kemampuannya untuk mengevaluasi peristiwa secara akurat, termasuk membuat penilaian tentang situasi dalam hal investasi. Dalam mengatasi bias, pengungkapan informasi akuntansi perlu dilakukan. Penelitian ini menggunakan penelitian deskriptif dan teknik pengumpulan data dokumentasi. Dalam penyampaian informasi akuntansi harus standar kualitas tinggi akuntansi dan keuangan dan pengungkapan nonkeuangan.

Kata kunci: Informasi Akuntansi, Bias Investor, Akrual.
\end{abstract}




\section{PENDAHULUAN}

Setiap bentuk transaksi dalam perdagangan saham tidak luput dari pengaruh perilaku investor. Hal ini sesuai dengan teori keuangan tradisional dan teori keuangan modern, yaitu pada teori keuangan tradisional, pendekatan dilakukan untuk membuat pasar menjadi efisien dan normatif. Sedangkan teori keuangan modern bertujuan agar investor dapat memahami cara pengambilan keputusan berdasarkan aspek psikologis. ${ }^{1}$

Studi ini memperluas penelitian yang ada dalam beberapa cara. Studi sebelumnya tentang hubungan antara pengungkapan dan harga penemuan fokus pada kompleksitas pengungkapan tekstual atau kualitas akrual dan memeriksa pengungkapan sehubungan dengan likuiditas, aktivitas perdagangan, dan pergeseran harga saham setelah tanggal pengarsipan 10-K. Studi ini untuk mengetahui hubungan pengungkapan informasi akuntansi dengan bias investor. Ukuran kualitas pengungkapan yang digunakan sebelumnya (diproksi dengan frekuensi perkiraan manajemen, peringkat AIMR analis, peringkat transparansi dan pengungkapan, perubahan dalam likuiditas pasar, dan berbagai pembacaan indeks kemampuan misalnya, didasarkan pada pengungkapan sukarela, ukuran, kesalahan pengukuran, dan subjektivitas dalam interpretasi. Analisis kami dimulai dari persfektif kuantitas informasi yang memungkinkan kami untuk mempelajari pengungkapan perusahaan kuantitatif tanpa beban keslahan pengukuran yang terkait dengan proksi untuk keterbacaan dan kualitas informasi yang digunakan di masa lalu. Akhirnya literatur sebelumnya, sebagian besar berfokus pada evaluasi pengungkapan incremental daripada pertanyaan yang lebih mendasar tentang kecukupan seluruh laporan perusahaan.

\section{METODE PENELITIAN}

\section{Sumber Data}

Penelitian ini merupakan penelitian kualitatif dengan pendekatan deskriptif. Penelitian kualitatif merupakan penelitian dengan menekankan pada hasil uji teori yang berasal dari pengukuran variabel-variabel penelitian. ${ }^{2}$

\footnotetext{
${ }^{1}$ Olsen. 1998, Earnings and Ethnicity in Trinidad \& Tobago, Journal Of Development Studies, Vol. 34.

2 Supomo, Bambang dan Nur Indriantoro. 2002. Metodologi Penelitian Bisnis, cetakan kedua, Yogyakarta: Penerbit BFFE UGM.
} 


\section{Sampel}

Metode pengambilan sampel menggunakan metode purposive sampling yang bertujuan untuk mendapatkan sampel yang representatif sesuai kriteria yang digunakan.

\section{Model Analisis}

Data yang digunakan yaitu data sekunder yang berasal dari jurnal akuntansi Indonesia dan jurnal akuntansi Cina. Teknik pengumpulan data adalah teknik dokumentasi yang memuat kejadian di masa lalu dan kajian literatur. Analisis data menggunakan analisis dekriptif.

\section{PEMBAHASAN}

\section{Pengungkapan Informasi Akuntansi}

Secara konseptual, pengungkapan merupakan bagian dari seluruh laporan keuangan yang berkaitan dengan langkah akhir dalam proses akuntansi yang berupa penyajian informasi dalam bentuk statemen keuangan. Evans dalam Fadli (2019), menyatakan bahwa maksud dari pengungkapan ini adalah penyajian informasi yang terbatas pada laporan keuangan dan catatan laporan keuangan itu sendiri, selain itu tidak termasuk dalam pengungkapan informasi akuntansi. ${ }^{3}$

Dalam penyampaiannya, data disclosure bertujuan untuk memberikan informasi penting dan relevan kepada pihak yang membutuhkan. Hal tersebut untuk memudahkan para pemakai laporan keuangan dalam mengambil keputusan. Blackwell, 1951 (dalam Blankespoor, dkk, 2018) Informasi apapun yang digunakan investor, memasukkan atau menggabungkan sinyal informatif secara bertahap akan meningkatkan penilaiannya. Dengan anggapan jika informasi akuntansi dapat membantu investor untuk membuat keputusan perdagangan dengan cara memaksimalkan return yang disesuaikan dengan risiko yang terjadi. ${ }^{4}$

Jika dikaitkan dengan informasi akuntansi, maka disclosure merupakan upaya transparansi suatu perusahaan untuk menyajikan informasi dalam bentuk laporan keuangan

\footnotetext{
${ }^{3}$ Ridho Darul Fadli, 2019. Pengungkapan dan Sarana Interpretif, Academiaedu.com (Online) di akses pada 21 Maret 2020.

${ }^{4}$ Blankespoor, dkk. 2018. Why Do Individual Investors Disregard Accounting Information? The Roles Of Information Awareness and Acquisition Cost, Journal Of Accounting Research, Vol. 57, No.1.
} 
maupun non keuangan secara jelas sehingga dapat menggambarkan secara tepat kejadiankejadian ekonomi yang dapat mempengaruhi pengambilan keputusan. Adapun tiga konsep pengungkapan informasi yaitu pengungkapan yang cukup (adequate), wajar (fair), dan lengkap (full).

\section{Sasaran Penyampaian Informasi Akuntansi}

Pengungkapan informasi akuntansi perlu mencakup bahasan yang berkaitan dengan upaya yang dilakukan manajer dalam melaporkan informasi akuntansi agar tidak merugikan investor. Dalam pelaporannya perlu dilakukan secara wajar dan lengkap. Pengungkapan yang wajar bertujuan untuk memberikan hasil laporan sebenarnya yang bersifat umum bagi setiap peinformasi akuntansi. Pengungkapan yang lengkap berarti menyajikan semua informasi akuntansi yang relevan bagi para investor. Namun, banyaknya informasi yang disajikan dapat membuat informasi menjadi tidak jelas dan sulit dipahami. Oleh sebab itu, maka pengungkapan informasi yang tepat ialah yang bersifat cukup, wajar dan lengkap. Penggunaan telekomunikasi yang baru juga dapat dilakukan untuk laporan audit. ${ }^{5}$

Hal-hal yang berkaitan dengan jumlah informasi yang disajikan dalam informasi akuntansi dipengaruhi oleh tujuan keuangan. Dalam SFAC No.1 (1980) mengungkapkan bahwa tujuan peinformasi akuntansi lebih luas dari lingkup informasi laporan keuangan. FASB menyatakan bahwa peinformasi akuntansi tidak sebatas informasi akuntansi saja, melainkan informasi yang berasal dari sumber ekonomi, hutang, laba periodik dan lainnya. ${ }^{6}$

Pengungkapan meliputi seluruh proses dalam pelaporan. Adapun metode yang digunakan dalam pengungkapan informasi masing-masing berbeda satu sama lain tergantung pada sifat dan pentingnya informasi yang dibutuhkan. Metode yang biasa digunakan dalam pengungkapan informasi diklasifikasikan sebagai berikut:

1. Bentuk dan susunan laporan yang formal

2. Terminologi dan penyajian yang terinci

3. Informasi sisipan

\footnotetext{
${ }^{5}$ Muhammad Bilal Farooq, 2019. Understanding How Managers Institutionalise Sustainability Reporting, Department Of Accounting: Auckland University Of Technology, Journal Of Accounting, Auditing \& Accountability, Vol. 32, No. 5, h. 0951-3574.

${ }^{6}$ Felipe Ramos dan Rodo Rafael, 2016. Earnings Management and Annual Report Readability, Canada: The University Of British Columbia, Journal Of Accounting and Economics, Vol. 63, h. 1-25.
} 


\section{Catatan kaki}

5. Ikhtisar tambahan dan skedul-skedul

6. Komentar dalam laporan auditor

7. Pernyataan direktur utama atau ketua dewan komisaris

Pengungkapan informasi akuntansi yang ada di Indonesia telah diatur dalam PSAK No.1 dan Surat Keputusan BAPEPAM No. Kep-38/PM/1996. Aturan tersebut merupakan pedoman pengungkapan yang wajib ditaati oleh setiap perusahaan yang telah publik dengan tujuan untuk mengatur setiap pengungkapan laporan akuntansi guna melindungi kepentingan investor dalam mendapatkan informasi yang relevan.

\section{Tingkat Pengungkapan Informasi Akuntansi}

Wolk et al., dalam Benson, dkk (2014) menjelaskan bahwa tingkat pengungkapan sebagai: "disclosure is concerned with information in both the financial statements and supplementary communications including footnotes, post-statement events, management's discussion and analysis of operations for the forthcoming year, financial and operating forecast, the summary of significant accounting policies, and additional financial statements covering segmental disclosure and extensions beyond historical costs. "7

Berdasarkan definisi di atas, maka dapat diketahui bahwa tingkat pengungkapan informasi akuntansi berupa laporan yang mencakup catatan kaki, kondisi setelah pengungkapan informasi, analisis manajemen terkait peramalan keuangan serta informasi akuntansi lainnya.

Jenis pengungkapan terbagi menjadi dua, yaitu pengungkapan wajib (mandatory disclosure) dan pengungkapan sukarela (voluntary disclosure). Pengungkapan wajib yaitu pegungkapan informasi berdasarkan peraturan yang berlaku (peraturan dari Badan Pengawas Pasar Modal/BAPEPAM). Menurut pengungkapan sukarela yaitu pengungkapan yang dipilih secara bebas oleh manajemen perusahaan sebagai dasar untuk membuat keputusan. ${ }^{8}$

Menurut Sutarto (2009), dalam menghitung kualitas peinformasi akuntansi

7 Benson, 2014. Cancers Of The Colon and Rectum: A Multidisiplinary Approach to Diagnosis and Management, New York: Demos Medical Publishing.

${ }^{8}$ Ariyanti dan Septiani, 2015. Pengaruh Corporate Governance dan Karakteristik Perusahaan Terhadap Praktik Pengungkapan Laporan Tahunan Peusahaan Manufaktur yang Terdaftar di Bursa Efek Indonesia, Semarang: Universitas Diponegoro. 
didasarkan pada indeks pengungkapan informasi akuntansi. Indeks pengungkapan yang digunakan berdasarkan informasi yang tersedia dalam laporan tahunan (annual report). ${ }^{9}$ Adapun pengungkapan informasi yang sesuai bagi investor diharuskan meliputi sifat cukup, wajar dan penuh. Selain itu, perlu dijelaskan bagaimana bentuk pengembalian kepada investor dari pihak perusahaan. ${ }^{10}$

\section{Jangkauan Pengungkapan}

Kualitas pengungkapan dapat dijadikan sebagai sarana penting dalam suatu informasi akuntansi. Namun, banyaknya informasi akuntansi yang ada justru dapat mempengaruhi kualitas pengungkapan yang ada karena dapat menimbulkan ketidakseimbangan informasi yang didapatkan oleh penerima informasi akuntansi (seperti pihak investor). Untuk mengatasi ketidakseimbangan informasi yang didapat oleh penerima informasi (khususnya bagi investor), maka terdapat tiga konsep pengungkapan yang dapat dijadikan sebagai usulan, yaitu:

1. Adequate disclosure (pengungkapan yang cukup), yaitu pengungkapan yang didasarkan pada peraturan yang berlaku sehingga tidak terdapat kecurangan.

2. Fair disclosure (pengungkapan wajar), yaitu pengungkapan yang dilakukan dengan maksud memberikan perlakuan yang sama kepada setiap penerima laporan keuangan.

3. Full disclosure (pengungkapan penuh), yaitu pengungkapan semua informasi yang bersifat relevan. Namun, bagi beberapa pihak pengungkapan penuh dapat memberikan dampak negatif karena terkesan berlebihan sehingga dapat mengaburkan informasi penting. ${ }^{11}$

\section{Penafsiran Akrual}

Akrual adalah penafsiran yang diskalakan dengan rata-rata total aset pada waktu $t$; dan $a l$ dan $a 2$ adalah konstanta, harga saham perusahaan-perusahaan itu relatif level akrual tinggi (rendah) dan akan relatif lebih tinggi (lebih rendah) daripada intrinsiknya nilai-nilai.

\footnotetext{
${ }^{9}$ Sutanto, Felicia Dwiputri dan Supatmi, 2009. Pengaruh Karakateristik Perusahaan Terhadap Tingkat Pengungkapan Intellectual Capital di dalam Laporan Tahunan (Studi Diponegoro) Journal Of Accounting Vol. 4, No. 3, Tahun 2015, h. 10.

${ }^{10}$ Eli Bartov, dkk., 2002, Comparative Value Relevance Among German, US, and International Accounting Standards: A German Stock Market Persfective, Journal Accounting, Auditing \& Finance.

${ }^{11}$ E.S. Hendriksen, 2002. Teori Akuntansi, Jilid 2, Edisi Kelima, Jakarta:Erlangga.
} 
Hubungan antara level akrual dan besarnya mispricing pasar adalah monoton. Implikasi serupa untuk analisis perkiraan pendapatan dapat diambil dari Bradshaw, Richardson, dan Sloan dalam (Su Xi, 2017). Kualitas akrual yang tinggi memberi manfaat yang lebih baik bagi investor luar terkait nilai perusahaan penerbit dan asimetri informasi antara emiten dan investor dan antara investor yang mendapat informasi dan tidak mendapat informasi investor dapat dikurangi.

\section{Pengungkapan Informasi Akuntansi Terhadap Bias Investor}

Ketidakseimbangan informasi yang dimiliki oleh manajer dengan investor sebagai peinformasi akuntansi mengakibatkan pemegang saham tidak dapat menilai secara detail prospek dan risiko perusahaan secara sempurna. Dalam hal ini, pemegang saham memiliki informasi yang lebih sedikit dibanding manajer disebabkan manajer sering memanfaatkan informasi yang dimilikinya untuk melakukan manajemen laba. Apabila tingkat pengungkapan informasi dilakukan secara penuh, maka dapat meminimalisir ketidakseimbangan informasi yang terjadi antara manajer dan peinformasi akuntansi.

Tingkat informasi dalam laporan informasi akuntansi dapat meminimalisir ketidakseimbangan informasi. Hal tersebut berakibat buruk bagi manajer karena dapat mengurangi kemampuannya dalam memanipulasi laporan keuangan perusahaan terutama untuk melakukan manajemen laba. ${ }^{12}$

\section{Karakteristik Kualitas Informasi Akuntansi Untuk Mengurangi Bias Investor}

Dalam menyajikan sebuah laporan keuangan dibutuhkan beberapa dasar untuk menilai kualitas dari suatu informasi akuntansi. Karakteristik ini sebagai penunjang informasi yang terjadi pada laporan akuntansi. Adapun karakteristik kualitas informasi yaitu sebagai berikut:

1. Relevansi

Relevansi mengacu pada berapa banyak pengaruh yang ditimbulkan untuk membantu proses pengambilan keputusan bagi pengguna laporan. Untuk mencapai kualitas informasi akuntansi yang relevan, maka ada dua unsur yang harus dipenuhi, yaitu: predictive value dan confirmatory Value. Predictive value, membantu

${ }^{12}$ A.N. Julianti, 2019. Laporan Akuntansi, Universitas Airlangga, Skripsi tidak diterbitkan. 
memprediksi hasil yang akan diperoleh di masa mendatang. Sedangkan confirmatory value, mengkonfirmasi kebenaran dari harapan sebelumnya.

Sebagai contoh, dalam laporan perubahan arus kas, perusahaan perlu menyajikan laporan tersebut kepada para pengguna informasi. Dengan adanya laporan yang relevan memudahkan peinformasi akuntansi dalam mengambil suatu keputusan.

\section{Dapat Diuji (Realibilitas)}

Realibilitas dikenal sebagai keandalan. Untuk mendapatkan suatu informasi yang akurat maka perlu dilakukan pengujian. Hal ini dilakukan agar informasi yang didapatkan dapat dijadikan sebagai gambaran nyata atas informasi yang tersaji. Kualitas informasi dapat dikatakan realible jika memenuhi unsur berikut ini:

a. Lengkap: laporan keuangan yang disajikan merupakan laporan penting yang disajikan dan telah sesuai dengan kriteria yang ditentukan.

b. Netral: Informasi keuangan yang dibuat berdasarkan kesepakatan dan kepentingan antara kedua pihak.

c. Bebas dari kesalahan: Informasi yang disajikan dalam laporan keuangan adalah laporan yang bebas dari bias.

3. Dapat Dipahami (Understandability)

Untuk dapat memahami informasi keuangan, maka perusahaan perlu menyajikan informasi laporan keuangan yang mudah dipahami oleh peinformasi akuntansi secara umum. Tujuannya untuk mempermudah para pengguna informasi dalam membaca dan memahami laporan akuntansi yang disajikan oleh perusahaan. Sehingga memudahkan para pengguna informasi dalam mengambil keputusan.

4. Komparatif (Comparability)

Perlu diketahui bahwa setiap laporan keuangan harus bisa dibandingkan dengan perusahaan lain. Tujuannya yaitu sebagai tolak ukur suatu perusahaan dalam menilai kinerjanya. Sebagai tolak ukur dalam menilai kinerja suatu perusahaan dengan perusahaan yang lain, maka diperlukan adanya sistem, aturan, dan kebijakan akuntansi yang sama. Hal ini berguna bagi para peinformasi dalam membuat keputusan.

\section{Kesalahan Yang Biasa Terjadi Dalam Pengungkapan Laporan Akuntansi}

Overreaction adalah kondisi Ketika investor dan trader bereeaksi tidak proporsional 
terhadap informasi baru mengenai sebuah saham. Jika reaksi mereka berlebihan dikatak overreaction dan jika harga tidak spontan merespon atau kurang bereaksi dari semestinya, maka disebut underreaction. Kedua kondisi ini menyebabkan harga saham tidak mencerminkan nilai fundamentalnya,

Dalam kasus overreaction, harga saham berubah drastis yaitu naik kencang saat mendengar kabar positif dan turun dalam Ketika muncul berita negatif. Namun, ayunan harga tidak berlangsung lama, harga saham perlahan tapi pasti kembali ke nilai intrinsik.

Contoh overreaction, sebuah emiten baru saja mengumumkan laporan keuangan tahunan yang mampu mengalahkan ekspektasi para analis dan investor beberapa rupiah atau sekitar 5\% dan tidak ada isu aksi korporasi lain. Jika kemudian para investor dan trader ramai berburu saham ini dan berani menawar hingga harga tertinggi, katakan puluhan persen dari harga sebelum pengumuman, mereka telah bereaksi berlebihan. Harga dalam waktu singkat mungkin saja ikut melonjak karena aksi beberapa investor emosional atau irasional. Namun, tidak lama, harga saham kembali ke nilainya. Walaupun naik, wajarnya hanya 5\%-10\%.

Reaksi berlebihan marak terjadi saat sebuah saham go-public. Literatur behavioral finance mencatat, beberapa saham naik hingga ratusan persen pada hari pertama melantai di bursa. Di urutan pertama ada theGlobe.com yang memberikan return hingga $606 \%$ sehari. Pada 13 November 1998, saham yang harga IPO-nya hanya US\$ 9, langsung diperdagangkan di US\$ 87 dan terus naik hingga US\$97, sebelum tutup di US\$ 63,5 pada hari itu. Harga theGlobe kemudian jatuh hingga US\$ 10 sen pada 2001. Tahun 2009 perusahaan tidak memperoleh pendapatan lagi dan utangnya sampai 500 kali nilai aset.

Di urutan kedua ada MarketWatch.com yang ditawarkan pada harga US\$ 17 di pasar perdana. Harganya sempat melesat menjadi US\$ 130 sebelum tutup pada US\$ 97,5 atau meroket pada $474 \%$ pada 15 Januari 1998.

Di bursa kita, overreaction tidak pernah sampai ratusan persen, karena ada maksimum kenaikan harga yang diperkenankan di hari pertama listing, yaitu dua kali autoreject pada perdagangan harian saham, yang 20\%-35\%. Jadi hanya bisa naik maksimal $40 \%-70 \%$.

Contoh lain adalah saham BJBR yang juga mengalami autoreject kanan di hari pertama melantai pada 8 Juli 2010 karena naik 50\% (maksimum). Harga masih terus naik dan berada di Rp. 1.600 tiga bulan kemudian. Setelah itu, harga berbalik arah dan hingga 
semester satu tahun ini tidak pernah ke harga tertinggi di tahun 2010. Pesan bias overreaction ini jelas, jangan mengejar saham yang sudah terbang tinggi apalagi pada eforia IPO. Waspadai bias overreaction setiap kali terjadi autoreject sebuah saham, bai katas maupun bawah.

Di posisi berlawanan, kita mengenal underreaction atau momentum. Dalam memprediksi masa depan, banyak orang terpaku kinerja masa lalu. Underreaction kerap terjadi Ketika investor dan trader memperoleh informasi terbaru mengenai laba perusahaan. Jika berita laba bersih per saham jauh dari ekspektasi, harga naik dan meneruskan kenaikan berhari-hari atau berminggu-minggu. Sebaliknya jika berita laba bersih per saham negatif, harga cenderung turun beberapa hari menuju nilai fundamentalnya.

Pada pasar modal, tingkat efisiensi dijadikan sebagai indikator dalam menilai besarnya return dari harga suatu sekuritas. Semakin tinggi tingkat efisiensi pasar, maka semakin baik informasi yang didapatkan oleh investor. Dapat dikatakan bahwa setiap informasi yang diterima dapat mempengaruhi keputusan investor dalam menilai harga suatu saham di pasar modal. Jika informasi yang didapatkan cenderung lebih sedikit maka keputusan investor dalam menilai harga saham akan lebih rendah (underwight) dari nilai yang sewajarnya sehingga saham menjadi undervalued dan hal tersebut menyebabkan adanya overreaction pada harga saham yang ada.

Menurut pendukung pasar efisien, overreaction dan underreaction bersifat acak dan tidak mudah diprediksi, sehingga sulit mendapatkan untung abnormal. Eugene Fama dalam dua artikelnya di tahun 1998 mengatakan overreaction di bursa sama umumnya dengan underreaction dan tidak ada polanya. Namun, pengikut behavioral finance memandangnya sebagai penyimpangan sistematis dari efisiensi pasar. Mereka menolak pandangan Fama, sambal menunjukkan sejumlah bukti empiris bahwa overreaction terjadi dalam jangka Panjang (1-3 tahun), sementara underreaction dalam jangka pendek (3-6 bulan). Kedua kejadian ini menandakan pasar tidak efisien. Ini berarti ada kesempatan memperoleh keuntungan di atas rata-rata pasar.

\section{Langkah Mengurangi Bias Investor dalam Pengungkapan Informasi Akuntansi}

Informasi akuntansi adalah bentuk tanggung jawab seorang manajer perusahaan pada pemilik saham (calon investor). Informasi akuntansi yang diberikan perusahaan kepada 
calon investor merupakan bentuk dukungan perusahaan kepada calon investor dalam membuat suatu keputusan.

\section{KESIMPULAN}

Adanya tingkat pengungkapan informasi akuntansi yang lebih luas merupakan harapan bagi para penerima informasi (investor). Namun hal ini nyatanya tidak sejalan dengan fakta dilapangan, dimana manajer sering terpengaruh pada biaya untuk mendapatkan informasi sehingga menyebabkan sering terjadinya bias dalam mengungkapkan informasi laporan keuangan pada suatu perusahan. Langkah pengungkapan laporan akuntansi seharusnya dapat dilakukan sesuai dengan standar yang telah ditetapkan sehingga dapat meminimalisir terjadinya bias dalam pengungkapan laporan akuntansi.

\section{DAFTAR PUSTAKA}

\section{Jurnal Utama}

Blankespoor, dkk. 2018. Why Do Individual Investors Disregard Accounting Information? The Roles Of Information Awareness and Acquisition cost. Journal of Accounting Research, Vol. 57. No. 1.

\section{Jurnal Pendukung}

Aida, Noviani. 2005. Analisis Pengungkapan Informasi Laporan Tahunan Pada Perusahaan Manufaktur yang Terdaftar di Bursa Efek Jakarta. Skripsi tidak diterbitkan.

Balakrishnan, K., J. Blouin, and W. Guay. 2011. Does Tax Aggressiveness Reduce Financial Reporting Transparancy?. www.google.co.id. Di akses 21 Maret 2020.

Bartov, Eli., dkk. 2002. Comparative Value Relevance Among German, US, and International Accounting Standars: A German Stock Market Persfective. Journal of Accounting, Auditing, and Finance.

Benson. 2014. Cancers of The Colon and Rectum: A Multidisiplinary Approach to Diagnosis and Management. New York: Demos Medical Publisihing.

Chang, L.Y., dan Lee, Y. J. 2012. The Influence of E-Word of Mouth on the Costumer's Purchase Decision: a Case of Body Care Products. Journal Global of Business Management. ISSN 1817-3819.

Hendriksen, E.S. 2002. Teori Akuntansi. Jilid 2, Edisi kelima, Jakarta: Erlangga. 
Fadli, Ridho Darul. 2019. Pengungkapan dan Sarana Interpretif. Academiaedu.com (online). Di akses pada 21 Maret 2020.

Farooq, Muhammad Bilal. 2019. Understanding How Managers Institutionalise Suistanability Reporting, Department of Accounting: Auckland University Of Technology. Journal Of Accounting, Auditing \& Accountability, Vol. 32., No.5.

Julianti, A.N. 2019. Laporan Akuntansi. Universitas Airlangga. Skripsi tidak diterbitkan.

Lang, Mark dan Lundholm Russell. 1993. Cross-Sectional Determinants Of Analysist Rattings of Corporate Disclosures. Journal of Accounting Research. Vol. 31. No 2.

Loughran, T. dan McDonald, B. 2011. Measuring Readability in Financial Disclosures. Forthcoming: Journal of Finance.

Olsen. 1998. Earnings and Ethnicity in Trinindad \& Tobago. Journal Of Development Studies. Vol. 34.

Ramos, Felipe. dan Rodo, Rafael. 2016. Earnings Management and Annual Report Readability. Canada: The University of British Columbia. Journal of Accounting and Economics, Vol.53.

Sutanto, Felicia Dwiputri dan Supatmi. 2009. Pengaruh Karakteristik Perusahaan Terhadap Tingkat Pengungkapan Informasi Intellectual Capital di dalam Laporan Tahunan (Studi Diponegoro). Journal of Accounting Vol. 4 No. 3.

Supomo, Bambang dan Nur Indriantoro. 2002. Metodologi Penelitian Bisnis, cetakan kedua, Yogyakarta: Penerbit BFFE UGM.

Tuanakotta, Theodorus M. 2011. Berpikir Kritis dalam Auditing. Jakarta: Salemba Empat. $\mathrm{Xi}, \mathrm{Su}$, dkk. 2017. Accruals Quality Underwriter Reputation, and Corporate Bond Underpricing: Evidence From China. China Journal of Accounting Research. Vol.10. 